\title{
Prevalence of asymptomatic bacteriuria among elderly diabetic patients residing in Chitwan
}

\author{
Jha BK ${ }^{1}$, YI Singh ${ }^{2}$, LK Khanal ${ }^{1}$, VC Yadab ${ }^{3}$, RK Sanjana ${ }^{1}$ \\ ${ }^{1}$ Lecturer, ${ }^{2}$ Professor and Head of Department, ${ }^{3}$ Assistant Professor, Department of Microbiology, College of Medical \\ Sciences, Bharatpur, Nepal
}

\begin{abstract}
Background: A retrospective study was done on Asymptomatic Bacteriuria (ASB), among elderly diabetic patients residing in Chitwan, Nepal from $1^{\text {st }}$ January 2006 to $12^{\text {th }}$ December 2006 . Diabetic patients above 40 years of age were included in this study where as below 40 years of age group were excluded.

Objective: To study the prevalence of ASB among elderly diabetic patients for the Bacteriological profile and their antibiotic susceptibility pattern.

Materials and methods: Urine sample was collected from 636 diabetic patients above 40 years age attending College of Medical Sciences Teaching Hospital for regular blood sugar estimation. Culture and Antibiotic susceptibility test (AST) were performed using standard microbiological technique. ASB was determined as presence of $\geq 10^{5} \mathrm{bacteria} / \mathrm{ml}$ in a culture of urine sample.

Results: The prevalence of ASB among diabetic patients in Bharatpur was found to be $9.43 \%$ (12.07\% in females and $5.08 \%$ in males). The most common bacterial isolate was Escherichia coli (41.66\%). Nitrofurantoin, Cefotaxime and Chloramphenicol were the most effective drugs for the majority of isolates.

Conclusion: The study shows necessity of regular urine culture to detect ASB, along with blood sugar estimation for diabetic patients to prevent them from further complications due to it.
\end{abstract}

Key words: Diabetic, ASB, Common pathogen and AST

Tnfections that are clinically apparent are called symptomatic infection, Asymptomatic infections go unnoticed by the patient himself due to lack of any clinical symptoms and signs ${ }^{1}$. Symptomatic infections make patient to visit doctor while asymptomatic infections may not get treatment as patient himself remains unknown about it. Hence, asymptomatic infections are equally important as symptomatic infections in regards to health hazard. Bacteriuria is a condition in which bacteria remain and multiply in urine, which is the second most common problem in developing countries, first being the respiratory infection ${ }^{2}$. Generally, infection of renal tract shows clinical symptoms like burning sensation during micturation, increased frequency of micturation etc. However, in some patients the clinical symptoms may remain unnoticed, to the patient themselves despite presence of significant bacteriuria. Such symptomless infection of urinary tract is called covert or asymptomatic bacteriuria. Symptomatic and asymptomatic bacteriuria are almost equally distributed, ranging from $40 \%-50 \%{ }^{3}$.

The Diabetes mellitus, characterised by high blood sugar level along with clinical symptoms like polyuria, polydipsia, polyphasia etc, is caused by an endocrine disorder prevalent all over the world. About 3.2 million deaths per year among elderly diabetics are occurring in USA only and this rate is increasing all over the world ${ }^{4}$. The diabetic patients are more prone to various infectious diseases. Asymptomatic bacteriuria is one of the common problems seen in diabetic patients preceding symptomatic UTI. Diabetes mellitus is a risk factor for developing complications of UTI such as renal papillary necrosis, emphysematous cystitis, emphysematous pyelonephritis etc, ultimately leading to renal failure ${ }^{5}$, about $10 \%$ of patients with UTI leading to renal failure ${ }^{6}$. The study may be beneficial here in Chitwan, where high diabetic population exists ${ }^{7}$.

After this study, suggestion may be formulated for diabetic and health care workers in Chitwan to improve the quality of life in diabetics. The extent of

\footnotetext{
Correspondence

Brajesh Kumar Jha

Lecturer, Department of Microbiology,

College of Medical Sciences Teaching Hospital Bharatpur,

Chitwan, Nepal

E-mail: baiju000@rediffmail.com
} 
asymptomatic bacteriuria in diabetics may be the guide to prevent further complications in them.

\section{Materials and methods}

A total of 636 diabetic persons above 40 years of age (306 male and 330 female) attending College of Medical Sciences teaching hospital for blood sugar estimation during OPD-hours from $1^{\text {st }}$ January $2006-12^{\text {th }}$ December 2006 are included in this study. The clinical history was taken according to questionnaire in the preformed. The fasting blood sugar level of the patient was estimated in the routine biochemistry laboratory. For detection of $\mathrm{ASB}$, the patients were advised to collect the freshly voided clean catch midstream urine specimen according to standard microbiological method. ASB was detected along with antibiotic sensitivity profile done by using National Committee on Clinical Laboratory Standards (NCCLS) methods ${ }^{8}$.

Aseptically collected clean catched mid-stream urine samples were observed macroscopically for turbidity. Urine routine examinations were done for different biochemical parameter by dipstick method. Microscopical examinations were done for cast, crystal, parasites and pus cells.

Culture: Wire loop having $3.26 \mathrm{~mm}$ diameter (Volume $0.004 \mathrm{ml}$ ) was used to inoculate on to Cystine Lactose Electrolyte Deficient (CLED) medium and Blood Agar plates were inoculated and incubated at $37^{\circ} \mathrm{C}$ for 16 to 18 hours. Colony count of more than or equal to 400 / loop of urine, indicative of significant bacteriuria was observed (Bacterial count more than or equal to $405 / \mathrm{ml}$ of urine considered as significant bacteriuria ${ }^{9}$ ).

\section{Biochemical Test}

Various biochemical tests were routinely done for identification of culture positive organisms. Preliminary tests were done like- Catalase, Oxidase, Coagulase. Conformatory test were also done like- oxidation/ fermentation test, triple sugar iron agar, nitrate reduction test, Simmon's Citrate medium, Christensens Urea agar, Sulpher- Indole -Motility medium and different sugar fermentation test and for fungal identification required special tests including sugar assimilation test were done for fungal conformation.

Antibiotic susceptibility: Test was done on Muller Hinton Agar plate. The method is based on Kirby \& Bauer's disk-diffusion principle. Various drugs used in AST for uropathogens were: ampicillin (10 mcg), gentamycin $(10 \mathrm{mcg})$, norfloxacin $(10 \mathrm{mcg})$ nalidixic acid (30mcg), Nitrofurantoin (300mcg), cefotaxime (30 mcg), co-trimoxazole $(23.75 \mathrm{mcg})$ chloramphenicol (30mcg). Antibiotic susceptibility was done according to NCCLS method ${ }^{8}$.

\section{Results}

A retrospective study was done on Asymptomatic Bacteriuria (ASB), among elderly diabetic patients residing in Chitwan, Nepal from $1^{\text {st }}$ January $2006-12^{\text {th }}$ December 2006. Diabetic patients above 40 years of age were included in this study where as below 40 years of age group were excluded from it.

1. Among 636 elderly diabetic patients included in this study, asymptomatic bacteriuria was seen in 60 patients. The prevalence of ASB among diabetics above 40 years age in Chitwan seemed to be $9.43 \%$

2. Distribution of ASB among male \& female patients.

Cases of ASB varied according to sex of the patients, with a higher incidence in female $(12.7 \%)$ then that in male $(5.8 \%)$ diabetic patients.

3. Bacterial profiles of ASB:

4. Report of Antibiotic sensitivity test:

Results of antibiotic susceptibility test showed Chloramphenicol, Cefotaxime and Nitrofurantoin to be most effective antibiotics for cases of ASB. Erythromycin and Nalidixic acid appeared to be moderately sensitive to the bacterial isolate.

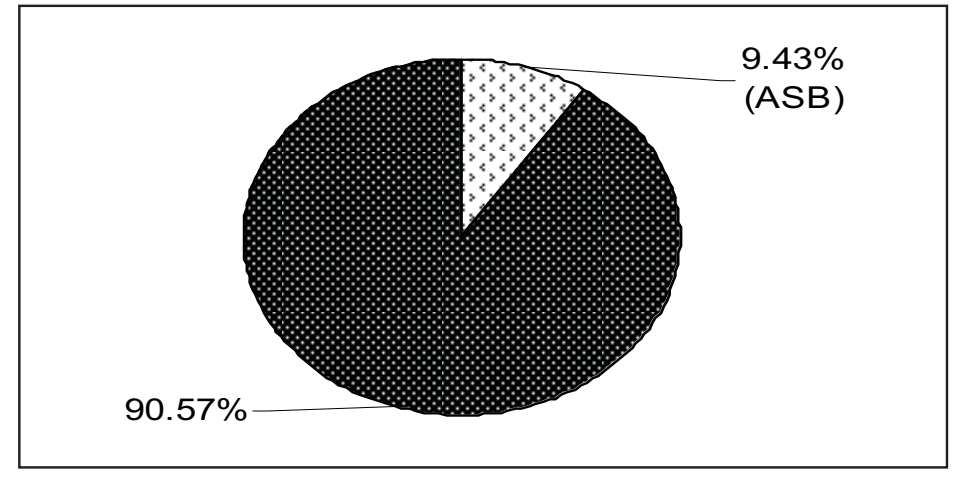

Fig 1: Prevalence of ASB among diabetics in Chitwan 
Table 1: Distribution of ASB in male and female diabetic patient.

\begin{tabular}{|l|c|c|c|}
\hline \multicolumn{1}{|c|}{ Features } & Total & Females & Males \\
\hline Patient & 636 & 330 & 306 \\
\hline Positive ASB cases & 60 & 42 & 18 \\
\hline Prevalence of ASB (\%) & $9.43 \%$ & $12.72 \%$ & $5.88 \%$ \\
\hline
\end{tabular}

Table 2: Microbes isolates from cases of ASB.

\begin{tabular}{|l|c|c|}
\hline \multicolumn{1}{|c|}{ Bacterial isolates } & Number of Isolates & Isolates in Percentage \\
\hline E. coli & 30 & $41.66 \%$ \\
\hline Kleb. pneumoniae & 12 & $16.66 \%$ \\
\hline Staph. saprophyticus. & 12 & $16.66 \%$ \\
\hline Candida albicans & 12 & $16.66 \%$ \\
\hline Staph. aureus. & 06 & $8.33 \%$ \\
\hline
\end{tabular}

Table 3: Sensitivity of microbial isolates to various drugs.

\begin{tabular}{|c|c|c|c|c|}
\hline $\begin{array}{l}\text { Name of the drugs and their } \\
\text { concentration }\end{array}$ & $\begin{array}{c}\text { Total no. of Gram } \\
\text { Negative Bacilli }\end{array}$ & $\begin{array}{l}\text { No. of isolates sensitive } \\
\text { GNB to the drug }\end{array}$ & $\begin{array}{l}\text { Total no. of Gram } \\
\text { positive cocci }\end{array}$ & $\begin{array}{c}\text { No. of Isolates } \\
\text { sensitive GPC } \\
\text { to the drug }\end{array}$ \\
\hline 1. Nitrofurantoin $(300 \mathrm{mcg})$ & \multirow{9}{*}{$42(100 \%)$} & $42(100 \%)$ & \multirow{9}{*}{$18(100 \%)$} & $18(100 \%)$ \\
\hline 2. Nalidixic acid (30 mcg) & & $18(42.86 \%)$ & & - \\
\hline 3. Cotrimoxazole $(23.75 \mathrm{mcg})$ & & $42(100 \%)$ & & $12(66.67 \%)$ \\
\hline 4. Cephotaxime $(30 \mathrm{mcg})$ & & $42(100 \%)$ & & $18(100 \%)$ \\
\hline 5. Norfloxacin $(10 \mathrm{mcg})$ & & $42(100 \%)$ & & - \\
\hline 6. Ampicillin $(10 \mathrm{mcg})$ & & $42(100 \%)$ & & - \\
\hline 7. Chloramphenicol (30 mcg) & & $42(100 \%)$ & & $18(100 \%)$ \\
\hline 8. Gentamicin $(10 \mathrm{mcg})$ & & $42(100 \%)$ & & - \\
\hline 9. (Erythromycin $(15 \mathrm{mcg})$ & & - & & $6(33.34 \%)$ \\
\hline
\end{tabular}

\section{Discussion}

Prevalence of ASB (9.43\%) among elderly diabetics in Chitwan district was found higher in this study. Uncontrolled blood sugar level (Latest WHO criteria FBS $>126 \mathrm{mg} / \mathrm{dl}$ ) is an important risk factor for ASB in diabetic patient ${ }^{10}$. Study done in Kenya National Hospital had shown symptomatic UTI, pyelonephritis and septicemia are followed by ASB in diabetic patients ${ }^{11}$. The high prevalence of ASB among diabetics in Chitwan may be due to uncontrolled blood sugar level in these patients. All the cases of ASB were detected from the patients having fasting blood sugar (FBS) more than $126 \mathrm{mg} / \mathrm{dl}$. High prevalence of ASB may occur due to re-infection among diabetics ${ }^{11}$. This study shows 12 out of 60 ASB case had history of kidney infection, 48 had hospitalisation in the past. Thus re-infection of the renal tract due to immune suppression in these patients may also be responsible for high prevalence of ASB. The prevalence of ASB among female was found higher than males $(12.07 \%$ vs $5.08 \%)$. Similar study was seen in university hospital of Netherland i.e. (12.32\% vs $6.00 \%)^{12}$. The high prevalence of ASB among female population may be due to absence of normal vaginal flora (Lactobacilli) as almost all the female participants included in this study were postmenopausal women and hence due to less acidic $\mathrm{pH}$ of vaginal surface in this group of women may be responsible for supporting growth of uropathogens. ${ }^{13}$ Another common reason for high prevalence among female diabetics may be due to poor hygienic conditions ${ }^{13}$. The fecal flora $E$. coli which contaminates perineum may have caused ASB. In summary, prevalence of ASB varies with time \& location, immune status \& sex of the patients, history of UTI; E. coli is most commonly encountered uropathogens covering up to $41.66 \%$ of renal infections. The result of this study showed $E$. coli to be most prevalent organism in ASB among diabetics. According to one researches in Kenya, the bacteriological isolates from cases of ASB among diabetics were GNB (66.71\%) including E. coli (40.00\%). ${ }^{11}$ The another study done on ASB among diabetics in Chile had shown, the bacteria isolated mainly were E. coli $(55.00 \%)$ the other being Klebsiella pneumoniae $(10.00 \%)$, Coagulase negative 
Staphylococcus (10.00\%), Enterococcus species (10.00\%) and Pseudomonas aeruginosa (5.00\%). ${ }^{14}$ The higher prevalence of E. coli may be due to poor hygienic condition of the patients and it is especially higher among females due to contamination of perineum through fecal flora. The other organisms isolated are Klebsiella pneumoniae, Staph. saprophyticus are common uropathogens but Staph. aureus is not pathogenic in normal individual diabetic patients. It was isolated from males having history of kidney infections and hospitalisation in the past. Isolation of these organisms may be due to incomplete treatment in the past and re-infection due to suppressed immunity. Along with ASB, 12 cases of asymptomatic candiduria out of 636 diabetic patients were found. The patients had uncontrolled blood sugar level (FBS >200 mg/ dl). Shukla I. et. al. found increasing prevalence of asymptomatic candiduria may be due to suppressed immunity among diabetic patients ${ }^{15}$. Other studies showed that the bacterial isolates were poorly sensitive to Ampicillin (33.00\%), Co-trimoxazole (33.00\%) only, but other drugs showed different patterns of sensitivity Nitrofurantoin (93.00\%), while other drugs like Gentamycin, Ceftazidime, Cefuroxime and Norfloxacin showed $>80.00 \%$ sensitivity pattern ${ }^{11}$. No report on elderly diabetic patient for ASB is available in Nepal. Drug resistance again now a days, is the biggest emerging problem in the microbial world. Various researches show resistance of uropathogens to Ampicillin, Cotrimoxazole and Tetracycline in various palces ${ }^{13}$. This study showed Nalidixic acid, Erythromycin and Cotrimoxazole as moderately sensitive drugs to uroisolates, the most effective drug being Nitrofurantoin, Chloramphenicol and Cefotaxime. The reason behind no isolation of any drug resultant bacteria may be due to less number of positive cases calculated in this study. The other region for isolating all drug sensitive bacteria may be due to out patients included in this study as drug resistance is more common in Hospital acquired infection ${ }^{16}$. Despite high prevalence of ASB in Chitwan drug resistance yet is not big problem for them.

\section{Recommendations}

1. Diabetic patients should be advised for regular urine examination for detection of ASB along with regular blood sugar estimation.

2. Diabetics should be advised to control the blood sugar level by regular medication.

3. Diabetics should be made aware of further complication in them and methods of prevention for improvement of their quality of life.

\section{Conclusion}

Resistant to Ampicillin, Cotrimoxazole and Tetracycline is reported by various workers. This study shows Nalidixic acid, Erythromycin \& Cotrimoxazole as moderately sensitive drugs to uroisolates. Nitrofurantoins, Chloramphenicol \& Cefotaxime are the most effective drugs as per antibiotic sensitivity test. There are reports of antibiotic resistant uropathogens in other studies. No isolation of resistant organism is found in our study. It could be because of less number of isolates and less period of study. Moreover the isolation from asymptomatic cases may not show resiststant organism, so it requires further study.

\section{References}

1. Park K. Infectious Disease. In: K. Park, editor. Park's Test Book of Preventive and social medicine. 18th ed. Jabalpur, India: B. Bhankot; 2005.p.311-5.

2. Kaspex H. Urinary tract infections. In: Dennis LK, Antony SF, Dan LL, Eugene B, Stephen B, J. Larry J, editors. Harrison's Principles of internal medicine. Vol. 2. 16th ed. New Delhi: McGraw-Hill; 2005.p. 1715-21.

3. Leigh D. Urinary tract infections. In: $G \mathrm{R}$ Smith, Charles S F Easmon, editors. Topley \& Wilsons principles of bacteriology, virology \& immunity. Vol. 3. 8th ed. London: Edward Arnold; 1990. p. 157-214.

4. Fedrick NM. Launch of diabetes action, Medicine society of state of Newyork. JAMA. 2005; 268: 240-8.

5. Mendoza L. Asymptomatic bacteriuria in type-2 diabetic women. Rav Med Chil. 2002. 130 (5): 1001-7.

6. Thomas M, Pacital, Gupta K. Risk factors associated with polynephritis. Am J pub Health. 2005; 142 (1): 20-7.

7. Alvine, Christ B. 'Diabetic complications \& associated risk factors' American diabetes Association complete guide to diabetes mellitus. N Engl J Med. 1999; 341: 1906-12.

8. James $\mathrm{S}$ Tan. Infectious complications in patients with diabetes mellitus. Immun Infect. 1995; 23: 200-5.

9. Sen C. Guide to clinical preventive service, disease prevention \& health promotion. J Assoc phys India. 2002; 50: 1013-6.

10. Collee JG, Duguid JP, Fraser AG, Marmion BP, Simmons A. Laboratory strategy in the diagnosis of infective syndrome. In: J. G. Collee, A.G. Fraser, B. P. Marmion, A. Simons, Mackie \& Mc cartney, editors. Practical Medical microbiology. Vol. (1).13 th ed. London: Churchill Livingstone; 1989; 84-90.

11. Kayima JK, Twahir A, Nienga E. ASB among diabetics attending Kenya National Hospital. East A Fr Med. 1996; 73 (8):524-6. 
12. Lawrence A, Frazee D. Management of ASB in diabetic patients. Drug information round. Asian J Diabet. 2003; 5 (1): 8-10.

13. Geerlings B, R Arsad. ASB in diabetic women diabetes care. 2003; 26 (7): 2209-10.

14. Kayima JK Twahir A, Nienga E. ASB among diabetics attending Kenya National Hospital. East A Fr Med J. 1996; 73 (8): 524-6.
15. Shukla I, Tiwari R, Agrawal M. Prevalence of $\beta$-Lactamase \& ESBL producing microbes. IJMM. 2004; 22 (2): 51-87.

16. P. Bijay. Diabetic Reprt. Chitwan Madhumeha Samaj- BNP-10, Feb 2005, 26-9. 